\begin{tabular}{ccc}
\hline & International Journal of Engineering \& Technology, 7 (4.38) (2018) $442-446$ \\
SPC & Website w ww.sciencepubco.com/index.php/IJET \\
Research paper & Technology \\
\hline
\end{tabular}

\title{
Labor Motivation and its Endogenous Level
}

\author{
V.N. Scherbakov ${ }^{1}$, A.V. Dubrovsky ${ }^{1}$, I.V. Makarova ${ }^{1}$, A.I. Zotova ${ }^{2}$, E.E. Nakhratova ${ }^{2}$ \\ ${ }^{I}$ Moscow Polytechnic University, P. Korchagina Str., 22, Moscow, 129626, Russia \\ ${ }^{2}$ Russian State Social University, V. Pika Str., 4, 1, Moscow, 129226, Russia \\ *Corresponding authorE-mail: scherbakov.v.n@mail.ru
}

\begin{abstract}
The article reveals key problems of motivational mechanisms that ensure economic growth, considering factor influences, including the endogenous level of a person. Efficiency of production and economic activity is considered from the viewpoint of revealing of the internal nature of person's motivational interests. The article reveals general framework of labor motivation as a science of effective management of structurally connected technical and technological as well as organizational and economic structures, where the necessity for self-regulation of labor activity to build dynamic multilevel relations is justified. The endogenous level of motivational interests is considered through the prism of the integrity of personal development, where the supreme goal is not only political and economic interests, but also moral ones. Justifying the fundamental approaches to the labor management in terms of efficiency (optimality), very important is taking into account the potential opportunities, since from the perspective of optimal use of labor resources, development of economic potential is the determinative element in the achievement of the performance measure (economic value and benefit). The development of value orientations and performance indicators is exactly the way that allows reflecting the limitations of existing methodological approaches to the mobilization of labor resources in the mechanism of economic management. Considering a new approach to labor motivation from the perspective of organizational and economic science, the main mechanism, as a rule, is the principle of the maximum viability of a one or another labor process regulation system. An alternative to this approach can be only the socio-economic system that meets the principles of optimal construction of economic interests and evaluation of each element in the overall results of production activities. Bringing such an optimum control action is almost impossible without the regulatory role of the state, because the sociopsychological motives of behavior are the driving force of decisions made, and therefore cannot reveal the effectiveness of labor potential and its motivational component, which would contribute to the confirmation of the principles of rational labor construction. The basic principle of labor motivation from the standpoint of optimization should be the labor theory of value and utility as the basis of value and labor economic motivations, revealing the economic nature of costs and the function of economic value and utility at the endogenous level of social and labor relations.
\end{abstract}

Keywords: Development; Economic activity; Economic growth; Efficiency; Endogenous level; Motivation; Policy.

\section{Introduction}

The core of economic policy is the revealing of human potential, genetically embedded by very nature. A number of economic studies are focused mainly on the technical and technological aspect of improving the production efficiency (techniques, technology, production organization) while underestimating the socio-economic issues (the status of the individual and the team, economic motivations, attitude to labor and property). Meanwhile, it is becoming more and more obvious that not only the implementation of techniques and advanced technologies as such determines the production efficiency, but also human capabilities. Human attitude to the labor becomes a decisive factor in development $[1,2]$. The major cause of the facts of inefficiency is that they are profitable or economically insensitive with respect to economic organizations, which "allow" these facts of inefficiencies. Delays in pursuing an effective economy course are directly linked to the survivability of specific criteria of "profitability" that is divergent from the interests of society. Often we have to deal with such an economic situation in which boosting scientific and technological progress, and improving product quality is economically disadvantageous for enterprises and associations [3]. That is why it has not been possible so far to get rid of the products valuation indicators, which reflects the overall production level rather than the products' structure and value.

It is for this reason that the improvement of economic motivation needs a framework concept that distinguishes between the main and subordinate attitudes, primary and derivative social and economic relations [4]. It seems that the main role in this concept should be played by mechanisms that reveal the performance potential of the economic entity. In this context it is wrong to put forward exclusively such an important category as material incentives. Although the material incentive is one of the most important motives [5], however, it does not reveal the endogenous level of human nature that ultimately leads to a decrease in performance. It is necessary evaluating the issues concerning incentives and motivation exactly from this standpoint, improving first of all the revealing mechanisms of the endogenous level of a person.

\section{Methods}

As a basic research method into motivation problems we used economic and mathematical modeling of technical and technological processes of production operation, a method of expert estimates, and also statistical and normative materials, which allowed 
revealing objective links between motivational interests and production efficiency.

The research purpose was identifying the managerial factor influences on the motivational mechanism of the economic process. In our study we used scientific works of domestic and foreign scientists in the field of economic relations of the lower economic level and the relationship with the development of technical and technological, as well as organizational and economic potentials The study is based on the data of social and economic development of the Russian Federation, statistical reporting data, and the main theoretical provisions of modern economic science. Within the research frameworks of the considered problem, the scientific reviews of economic institutes of the Russian Academy of Sciences, proceedings of economic forums, symposia, as well as scientific developments of universities and individual scientists were used. It should be emphasized that the study of this issue was carried out in the context of further development of the marginal utility theory and labor theory of value.

The research tools included analytical and statistical review materials, reference and analytical flowchart calculations of structural changes of the factor influencing the effectiveness, processing methods of analytical data and expert calculations of appraisal ratios of motivational interests of the human, as well as catalog (list) of analyzed documents.

Units of analysis were semantic units reflecting the positive and negative attitude of the target function of the motivational behavior of the subject in the economic structure of the market.

Unit of account was the number of units of analysis expressed in pieces.

Indicators were words that reflected the essential content of the motivational mechanism and its factor manifestations in the economic process structure. While conducting analysis, the ideas embedded in the commentary and their conceptual meanings were taken into account.

\section{Results}

In the course of the conducted study, it was revealed that radical revolution is needed in the socio-economic structure, the elimination of negative trends in the existing type of production and economic relations of all sectors of the economy $[6,7]$. The nature of the socio-economic structure needs to be changed taking into account specific conditions of functioning and developing economic organism of society. The material basis of the existing relations objectively complicates the development of full-fledged economic motivations, adequate to the effective development process. The way market participants behave is determined by value orientations and the end in itself of social and economic development.

Domestic literature has long been involved in investigation of the motives, needs of individuals, the causes of deviant behavior, ways of improvement, and moral development of the human person. Without the improvement of the motivational aspect of economic behavior, one cannot expect overcoming the spiritual, economic, and political crisis [8].

Motivational sphere of a person in terms of its sophistication is assessed by the following parameters: breadth, flexibility, and hierarchization. The breadth of the motivational sphere is understood as the qualitative variety of motivational factors-motives, needs, and goals. The broader the variety of person's motivations is, the more developed his motivational sphere is. Breadth is a variety of potential scope of items that can serve for a given person as a means of meeting his current needs [9].

The flexibility of the motivational sphere is the mobility of connections existing between different levels of hierarchical organization of motivation: between motives and needs, motives and goals, as well as needs and goals

Finally, the hierarchization of the motivational sphere, in our opinion, characterizes the structure of each organizational level of motivational formations taken separately. Needs, motives, and goals do not exist as the same sets of motivational dispositions. Some dispositions (motives, needs, and goals) are stronger than others and occur more often; others are less frequently actualized. The more differences in the strength and frequency of actualization of motivational formations of a certain level are, the higher the hierarchization of moral incentives is.

Its content is inextricably linked with the need to increase the human activity [10]. Here, the paradox of the current situation is that this important problem has actually been out of the field of vision of psychological theory. The category of "moral incentives" is still poorly developed. In fact, the research of this concept is just beginning.

A significant variety of opinions expressed on the content of moral incentives are primarily due to the complexity of the very subject under the study [11].

In our opinion, moral incentives have an objective-subjective essence, expressing a dual kind of dependence: on the one hand, the dependence of subjective motivational forces on the objective relationship of reality, and on the other hand, the focus of the person on the content of the goals of activity, determined by his endogenous level. In accordance with this, moral incentives act as determining factors of the motivational behavior development in the economic structure of the market.

In our opinion, moral incentives are a specific function performed by them in the course of activity rather than qualities ontologically linked to objects or ideas. The concept of morality characterizes the process of transformation of spiritual factors from a potential form to its active form [12]. Therefore, it would be wrong to identify moral incentives with the phenomena of consciousness (ideas, views, assessments, etc.), irrespective of their functional role as motivating factors in the human activity. Attention should be paid to the purposive character of moral incentives, as the latter are always aimed at achieving specific objectives [13]. Moral incentives act as purposefully used measures to activate moral motives. Therefore, it is necessary to consider moral incentives as a system of determining factors. Moral incentives are not limited to the realm of consciousness. They include in their structure concrete, real forms of public life. In our opinion, one can say that moral incentives are a social category, by means of which direct drivers of human activity, formed on the basis of needs and interests, are designated [14]

In the system of moral regulation of the labor process, an important role is given to the public recognition of the active merits of the individual. Consequently, the moral value of wages, being mediated by moral consciousness, is revealed only in the context of moral relations. Moral stimuli should be considered simultaneously in terms of the interaction of psychological factors and internal moral satisfaction of the individual. These aspects of moral incentives express various links of functional relations within the framework of interaction of the individual with the social environment.

Thus, in this aspect, the differentiation between incentives and motives as objective and subjective phenomena has a reasonable basis. The meaning-making function of the motive is that different individuals, due to the specifics of their interests, perceive differently the same effects of social factors. However, this disparity of incentives and motives should not be absolutized.

Hence it becomes clear that the psychological classifications of motives into "meaning-forming" and "nonmeaning-forming" are not adequate to the social behavior of individuals. Thus, A.N. Leontiev writes: "... we will call some motives to be meaningforming, others, coexisting with them, fulfill a role of motivational factors (positive or negative), sometimes emotionally charged, efficient; however, they are deprived of meaning-making function."

Leontiev considers social motives to belong to the first group, while material reward - to the second one. "Both these motives, although coexist, but lie as if in different planes... As for material incentives, this motive, of course, is also present, but only in the function of stimulation. Although it induces and "dynamizes" the 
activity, it is devoid of the main function, namely a meaningmaking function" [15].

In our opinion, labor motivation is a meaning-making factor of activity, and material incentives have for the individual an unambiguous meaning-making. This reflects a subjective conditionality of the impact of financial incentives. At that, the subject matter of this conditioning should be sought in the psychological mechanisms of incentives [16]. Here it is necessary to recognize that the subject possesses assessing ability or subjective selectivity with respect to objective life-sustaining activity factors.

Each human activity has a certain structure, in which one always identifies actions and operations as the main activity components. Action is called part of the activity, which has a completely independent purpose realized by human. An operation is a way of performing an action.

Means of implementation person's activities include the tools he uses. The development of the means of activity leads to its improvement, resulting in a better quality of activity [17].

Returning to the problem of moral incentives, it should be emphasized that any system of stimulation is focused on the person. At the same time it is important to take into account in what capacity a person is considered. For example, recognizing a person as a subject of labor activity, he can be considered as no more than a carrier of labor. With this approach, the stimulation is carried out mainly through wage and is narrowly interpreted economically as directly consumer relationships.

In our view, this approach is confined. Here a moral concept of incentive is required. The moral approach also refers to the person, but the universal person, perceived in all the wealth of his vital interests. Such a person is not programmed by economic need, but has his own, personal goals and interests, far beyond the immediate needs. In the acts of stimulation, it becomes especially important to ensure conditions for more complete revealing of human abilities, development of his creative activity, selfactualization and self-improvement, recognition and respect from the surrounding people [18].

Moral approach means further transition from direct to indirect acts of stimulation, since it implies going beyond the needs satisfied in the course of labor activity. It becomes necessary to take into account the diversity of noneconomic interests of the individual.

One of the most important aspects of moral incentives is the view of the relationship of public and personal interests in motivating activities. It has already been noted that moral incentives aim at implementing public interests. But this does not mean that public interests act as opposing the interests of the individual. Here it is necessary to take into account the following aspect: the very implementation of public interests acquires personal value significance in terms of the moral sense. In this regard, personal interest should be "rehabilitated" as a fully-fledged object of moral activity. "Personal interest in the pursuit of personal happiness is an important prerequisite and condition for the existence of morality. The latter is based not just on the public interest or the interest of the public as a whole, but on a combination of personal interest with the public interest, the unity between them."

In our view, the logic of opposing moral motive to personal interests is not rooted in morality itself, but in real life relationships. Moral motives are of historical origin. They are the individual transformed through social relations. Therefore, the contradictions of the moral subject's motivation can be understood only with a specific historical approach to their study [19].

As known, in modern conditions, the principles and norms of morality often act as externally imposed "moral barriers" for those drives, desires and aspirations, following which people should seek to meet their needs and interests. The transformation of social demands of morality into motives of personal behavior is associated with a sense of inner satisfaction. In this regard, the action of moral incentives involves not only the awareness of moral goals and public interests, but also the actualization of moral and psychological mechanisms of self-assertion and self-respect [20].
The social mechanism for determining the prestige of a person is a collective mind, which assesses the behavior of each member of the team in accordance with moral ideas, principles, and norms. Moral assessment has great incentive value.

The substantial diversity of views expressed on the content of incentives is primarily due to the complexity of the subject matter. In our opinion, the motives of economic behavior have an objective and subjective essence, which expresses a dual kind of dependence: on the one hand, the dependence of subjective motivations on objective relations of reality, and on the other hand, the focus of the very subject on the content-related goals of activity. In accordance with this, incentives act as determining factors of the social environment and as moral motivations of the subject.

The fallacy of many formulations that reveal the meaning of incentives is not only that they are presenting exclusively on the side of objective relations or exclusively on the side of consciousness, but that they are interpreted as ontological (metaphysical - outside of movement, change, and development) essences [21]. In our view, incentives are not qualities, ontologically related to objects or ideas, but a specific function performed by them in the course of their activities. The concept of incentives characterizes the process of transformation of spiritual factors from a potential form into economic activity form of people.

The economic principle, based on the endogenous level of human behavior motives, as noted, was formulated in many studies very long time ago. This principle has found full application in the studies of physiocrats, who turned economic science into a system of certain structured and interdependent relations [22]. Therefore, prejudices against the "endogenous approach" to development are based in a number of cases simply on a ridiculous misunderstanding: the motivations for effective economic activity simply cannot ignore the human nature that permeates economic life from top to bottom. Therefore, the genetic approach is based on conscious activity and conscious goals that a person sets in the process of labor. In this regard, it should be noted that human not only changes the shape of what is given by nature, but also carries out his conscious goal, which as a law determines the way and nature of his actions and to which he must submit his will. The heart of the conscious goal includes the end in itself of development as an endogenous level of motivation mechanism, manifested in all economic relations [21]. These relations cannot but be subjective, since they contain the endogenous nature of development, which, according to Hegel, is manifested by random and arbitrary connections. It was in such conditions that the high moral philosophy of A. Smith was formed, which has found the most complete embodiment in the "Theory of moral sentiments" and indirect reflection in "An inquiry into the nature and causes of the wealth of nations." Smith was well aware that the concern for common interests, the interests of state power, national glory, the development of domestic industry and trade often covered the selfish interests of traders and manufacturers wishing to realize their private benefits to the detriment of the fair interests of society [23].

The subsequent development of the principles of effective economy management went on the way of expanding the range of motives that controlled the economic life of people, primarily on the way to identify such "cohesion" of passions and motives that were difficult to express only in the economic language. After Smith, "self-interest" was no longer recognized as an integral part of the rational behavior model, and the selfish (material) motive is no longer recognized as the main or decisive impetus. Thus, the systematist of Smith's ideas, French economist J.B. Say wrote: "It is unfortunate that social mores, disastrous habits of the country with which a person is bound by his birth, status, and attachments subordinate to their influence even the most developed, the most capable people. Only a very few people, quite firm in their beliefs and independent in their financial standing, act only on their principles and are guided only by their beliefs. The majority follow, contrary to their desires, a reckless crowd, which, without thinking about anything, do not notice that if the ordinary needs of life are 
satisfied, happiness is not in the idle pleasures of luxury, but in the measured use of their physical and moral abilities."

This aspect was especially in the focus of Marginalists, for whom the motivation of economic behavior was an essential attribute of any economic system. It is for the sake of "healing" the ailments of the economic structure of life that motivational aspect should be studied deeply, especially in connection with the transition to economic pluralism, differentiating the motives of economic behavior, expressed, in particular, through the monetary assessment of economic benefits. Thus, A. Marshall, revealing the research subject of modern "economists", emphasized exactly the intersection of various driving factors by which people were guided in a competitive environment, the destructive effect of which was not always accompanied by creation [24]. Stressing that economic science studies partly the process of wealth creation, and partly - the appointment of man, Marshall believed that the leading motives were both selfish aspirations and religious enthusiasm. Consequently, economic science is, on the one hand, a study of wealth, and on the other hand, it forms part of human-focused research. The human character is formed in the course of his daily work and under the influence of the material resources created in this process, and to a much greater extent than under the influence of any other factors, excluding religious ideals; the two great forces that formed the world history were religion and economy [25].

Speaking for the development of free economic activity, at the same time Marshall pointed to the possible changes in motivation, resulting in the detection of destructive forces caused by competition, but "with all that the most stable incentive to conduct economic activities is the desire to get paid for it, which is a material reward for the work. This money can then be used for selfish or altruistic, noble or lowly purposes, and here we find the manifestation of the versatility of human nature. However, the motive is a certain amount of money. It is this definite and precise monetary dimension of the most sustainable incentives in economic life that has allowed economic science to be far ahead of all other sciences that study human beings."

Thus, material motives of economic activity have become the basis of modern discussions exactly when considering driving factors in both production of material goods and the distribution of wealth [21]. Money began to be used to measure not only the level of material wealth, but also the very impelling force in the course of economic competition. Not only the beneficial effects of consumer goods, but also the activity of each member of society, are measured by monetary resources of consumers.

However, the motivation of economic behavior is extremely complex and cannot be reduced to purely economic indicators. Monetary assessment of labor plays an exclusively integrating function, and therefore can serve as a generalizing indicator of both labor efficiency and the successful activity of the entrepreneur (wages and business rent).

\section{Discussion}

When considering the labor motivations in terms of revealing the wealth of the human nature and its endogenous level and perceiving the person as a true end in itself, we emphasize that the economic factors affecting motivational behavior of a person may not always be the supreme goal in making an administrative decision, because person must be subordinated to the moral component, which determines among other things the development of the integrity of the individual, i.e. the motivational basis is determined always by the competing objectives of economic and noneconomic interests [26]. Value orientations of labor motivation and evaluation indicators reveal the endogenous level of the economic category of "value" and its subject matter in a fundamentally new fashion that serves the basis on which the motivational mechanisms of labor relations should be built. The processes of motivational relations occur on the one hand, in heterogenic way, that is dissimilarly, and on the other hand - they are controlled by some regulatory force. Therefore, the role of the state consists in providing protectionism of those directions which ensure the construction of effective mechanisms in terms of both form and meaning, that is, a special role is given to the motivation for highperformance and high-quality labor in a competitive market environment [27].

\section{Conclusion}

As shown by numerous studies, the motivation of economic actions is determined by the complex circumstances, not always associated with remuneration for labor. Wages for labor or business rent are not always the determining motives for economic behavior. But, the same surveys have shown that unpaid wages or lost profits cause extremely negative responses in the behavior of economic entities leading to rallies, strikes, acts of civil disobedience, etc. Similarly, the "nonpayment crisis" causes huge interruptions in economic life, reduces the level of entrepreneurial activity, and even simply leads to the curtailment of production.

Thus, it is objectively necessary to develop, deepen, and enrich the motivational mechanisms to achieve high results in production and economic activity. Revealing the problems of the motivational mechanism represents a study of complex functional relationships of development factors. It is obvious that the production process should be associated with the motivational factor, which is a link in the hierarchy of economic relations. The scientific character of the present approach consists in combining the production process with human nature and the revealing the motivational aspect of human activity aimed at ensuring the functional interdependences that predetermine the level of production efficiency and economic growth.

\section{References}

[1] Nakhratova EE, Ilina IY, Zotova AI, Urzha OA \& Starostenkov NV (2017), Analysis of the relevance of educational programs for applicants and the labor market. European Research Studies Journal 20(3), 649-659.

[2] Evstratova T, Shalashnikova V, Starostenkov N, Nakhratova E, Zotova A \& Ziroyan M (2016), Practical aspects of volunteer movement development in Moscow. Research Journal of Pharmaceutical, Biological and Chemical Sciences 7(3), 2073-2081.

[3] Strielkowski W \& Höschle F (2015), Evidence for economic convergence in the EU: The analysis of past EU enlargements. Technological and Economic Development of Economy 22(4), 617-630.

[4] Nakhratova EE, Ilina IYu, Zotova AI, Stepanov MS \& Dusenko SV (2017), Modern peculiarities of SWOT analysis when taking management decisions by Russian top managers. International Journal of Applied Business and Economic Research 15(7), 187-194.

[5] Rogach OV, Frolova EV \& Ryabova TM (2017), Academic competition: Rating race. European Journal of Contemporary Education 6(2), 297-307.

[6] Kryukova EM, Makeeva DR, Atamanova MA \& Shadskaja IG (2013), Financial mechanism of housing and utilities infrastructure. Life Science Journal, 10(4), 790-794.

[7] Zaernzhuk VM, Kryukova EM, Bokareva EV \& Chernikova LI (2014), Study of theoretical approaches to banking financial intermediation and directions of its development in Russia and abroad. World Applied Sciences Journal 30(12), 1746-1748.

[8] Apanasyuk LA, Egorova EN, Kryukova EM, Mosalev AI \& Mukhomorova IV (2017), Socio-ecological education as a factor of economic development. SGEM International Multidisciplinary Scientific Conference on Social Sciences and Arts 1-3, 971-978.

[9] Shcherbakov VN, Kireev SV, Litvinenko IL, Zelinskaya MV \& Fateva SV (2017). Economic clusters: Concepts and characteristic features. International Journal of Applied Business and Economic Research 15, 123-132.

[10] Rogach OV, Frolova EV, Demina SV \& Ryabova TM (2018), Gamification use for government authority employee training. Espacios 39(22), 31-41.

[11] Shkurkin D, Ryazantsev S, Gusakov N, Andronova I \& Bolgova V (2016), The Republic of Kazakhstan in the system of international 
regional integration associations. International Review of Management and Marketing 6(6), 174-179.

[12] Steiner M (1998), Clusters and regional specialization. London: Pion.

[13] Frolova EV, Ryabova TM \& Rogach OV (2017), Bureaucrat image in Russia. Journal of Advanced Research in Law and Economics 8, 3(25), 52-59.

[14] Roelandt T \& Den Hertog P (1999), Boosting innovation. Paris: OECD Publications, 9-23.

[15] Simonin PV, Bogacheva TV, Sopilko NYu, Kutlyeva GM, Vetrova EA \& Povorina EV (2017), Institutional traps of wages and income inequality. Journal of Applied Economic Sciences 12(8), (54), 2202-2217.

[16] Porter M (1998), On competition. Boston, MA: Harvard Businesss School Pub, 1998.

[17] Gumerov AV, Mukhomorova IV, Sadykova RR, Fatikhova LE, Chikisheva NM, Simonova LM \& Alenina EE (2015), The program client voice as a tool of business structure innovations. Journal of Sustainable Development 8(3), 263-270.

[18] Latham W (1976), Locational behavior in manufacturing industries. Boston, MA: Springer US.

[19] Le Heron R \& Harrington J (2005), New economic spaces: New economic geographies. Farnham, UK: Ashgate Pub Co.

[20] Groen A, New technology-based firms in the new millennium. UK: Bingley, Emerald, 2012.

[21] Shcherbakov VN, Korsakov MN, Shichiyakh RA, Kireev VS \& Bondarchuk NV (2017), Research project management as the main tool of innovative management. International Journal of Applied Business and Economic Research 15(3), 1-11.

[22] Hong S, Oxley L, McCann P \& Le T (2016), Why firm size matters: Investigating the drivers of innovation and economic performance in New Zealand using the business operations survey. Applied Economics 48(55), 5379-5395.

[23] Crouch C (2001), Local production systems in Europe. Oxford: Oxford University Press, pp. 161-211.

[24] Bogoviz AV, Ragulina YV \& Kutukova ES (2016), Economic zones as a factor of increased economic competitiveness of the region. International Journal of Economics and Financial Issues 6(8), special issue, 1-6.

[25] Centonze A (2010), Transitional cluster development: A case study from the New York wine industry. Economic Development Quarterly 24(3), 251-260.

[26] Bolnokin V, Storozhev V, Vasilenko S, Kobersy I, Shkurkin D \& Evtushenko V (2016), Model for optimization elements system. International Journal of Applied Engineering Research 11(4), 2879. 2884.

[27] Gladkaya EA, Egorova EN \& Torsunova ER (2017), Using economic and mathematical methods during formation of construction cluster. Contributions to Economics, 243-250. 